\title{
Satisfaction Assessment Tool for Obstetrics Triage(SATOT): Development and Psychometric Properties
}

\section{Farzaneh Rashidi Fakari}

Shahid Beheshti University of Medical Sciences School of Nursing and Midwifery https://orcid.org/0000-0001-7497-4180 Masoumeh Simbar ( $\sim$ msimbar@gmail.com )

Shahid Beheshti University of Medical Sciences https://orcid.org/0000-0003-2843-3150

\section{Research article}

Keywords: Satisfaction, Obstetrics Triage, Questionnaire Development, Psychometric, Properties of Questionnaire

Posted Date: October 5th, 2020

DOl: https://doi.org/10.21203/rs.3.rs-75608/v1

License: @ (i) This work is licensed under a Creative Commons Attribution 4.0 International License. Read Full License 


\section{Abstract}

Background: Obstetrics triage is one of the major concerns of hospitals and health care providers. Satisfaction with the services received is a consequence and an important indicator in the assessment of service quality. However, service providers should frequently assess client satisfaction and use high reliability and validation tools to meet clients' needs. Thus, the aim of this study was designing and psychometric Satisfaction Assessment Tool for Obstetrics Triage.

Methods: The current study is methodological research and was conducted by the exploratory sequential mixed method in two qualitative and qualitative stages. The first stage using a content analysis approach for describing the concept of satisfaction and then the initial items were extracted and the questionnaire was designed. In the second stage, the designed questionnaire was conducted on 200 subjects referring to obstetrics triage in terms of face validity, content validity, and construct validity by exploratory factor analysis. Reliability was calculated with internal consistency (Cronbach's alpha) and stability with ICC.

Results: Ten items were extracted from the content analysis. Ten items were evaluated to face and content validity and no items were deleted. In the construct validity, one item was eliminated and nine items were extracted in two factors of structure and process satisfaction that explained $63.40 \%$ of the total variance. The numerical CVR of all items was above 0.49 and the I-CVI Modified Content Validity Index $(\mathrm{K} *)$ of all items ranged from 0.86 to one, and the S-CVI score was 0.97 . The intra-cluster correlation coefficient was 0.884 and Cronbach's alpha was 0.793 .

Conclusion: The SATOT is a valid and reliable questionnaire for the assessment of the satisfaction of clients with obstetrics triage. The questionnaire consists of nine items with two dimensions (process and structure satisfaction) of five-point Likert scoring is a simple and easy-to-use tool. This questionnaire may help health providers and policymakers identify problems and challenges in triage that led to dissatisfaction and inappropriate outcomes and take appropriate action as appropriate.

\section{Background}

The triage is the preliminary evaluation process for delivering high quality, timely, effective services based on the client's clinical conditions and resources available(1). The obstetrics triage unit provides inaccessible medical care in emergencies(2). The obstetrics triage unit has multifunctional aspects of pregnant women acceptance, fetal assessment, acute midwifery emergencies, and performance evaluation, and various methods of gynecology and midwifery(3). Obstetrics triage is one of the major concerns of hospitals and health care providers (3-5). However, proper triage will increase the quality of service and increase efficiency $(6,7)$.

Although the quality of services provided to clients is one of the most important health priorities(8). According to the Donabedian model, client satisfaction is a mediating consequence that is affected by service quality $(9,10)$. Therefore, satisfaction with the services received is an important indicator in evaluating the quality of services provided (11). Quality is a multifaceted concept, an important aspect of which is patient satisfaction (12). Patients' satisfaction is the set of patients' experiences of the health care system and considering the level of satisfaction and continuous assessment of this satisfaction is essential in all planning for providing services and facilities (13). In recent years, measuring the quality of health services has become increasingly important from the patients' perspective, as it is the patients' right to comment on the services they receive (14). Therefore, service providers should regularly assess client satisfaction and use high reliability and validation tools to meet clients' needs $(15,16)$. Evaluation of an organization's performance provides the basis for improvement and correction of organizational harmful damages, increasing productivity, and satisfaction. It also identifies efficient and effective activities and challenges (17).

Studies have shown that triage personal's environment and behavior are factors affecting clients' satisfaction with obstetrics triage (18). While little information is available on obstetrics triage satisfaction, perhaps one reason for the lack of such information is the lack of a valid and reliable tool for assessment of obstetrics triage satisfaction and a poor understanding 
of obstetrics triage satisfaction. Therefore, this study aimed to design and psychometric evaluation of obstetrics triage satisfaction.

\section{Methods}

The present study is part of a larger study of methodological research conducted in an exploratory sequential mixed method in two qualitative stages (designing obstetrics triage satisfaction tool) and quantitative (examining psychometric properties of obstetrics triage satisfaction tool).

Inclusion criteria included all recipients of obstetrics triage services at Shahid Beheshti University of Medical Sciences teaching hospitals in Tehran. Sampling was done from June to November 2019.

\section{Tool design}

Waltz's four-step tool design was done. The deductive inductive method was used to extract the items of obstetrics triage satisfaction assessment. To illustrate the concept of obstetrics triage satisfaction and its dimensions, the qualitative method of content analysis was used, and then a literature review was performed. Semi-structured interviews were conducted with 23 participants including individuals referring to obstetrics triage, triage personal, and key obstetrics informants. Participants were selected with maximum diversity in terms of age, education, and field of study. The interview started with the general question 'How was the obstetrics triage service? and continued with more specific questions. The duration of each interview was 15-20 minutes. The number of interviews continued until information saturation. Data analysis was done, as data was collected, based on steps proposed by Graneheim and $\operatorname{Lundman}(19,20)$. After each interview, the interviews were transcribed after listening several times; they were typed and then entered into the MAXQDA10 software. The transcripts of the interviews were coded several times of re-reading by the researcher using an open coding system to produce the first categories. For this purpose, the texts of the interviews were first divided into semantic units, and then different codes were compared based on their similarities and differences and categorized into categories. Then, a comprehensive review of the studies was done using the deductive approach and key terms of triage, obstetric or midwifery triage, satisfaction, questionnaire, scale, index, and checklist were searched in PubMed, Proquest, Science Direct, Ovid, Google Scholar, Magiran, Iranmedex, Irandoc databases. Inclusion criteria included related Persian or English articles, regardless of the time limit. Articles were then reviewed and items related to obstetric triage quality not included in the phrase pool were added to the main items of the questionnaire. The initial tool was then prepared for validation.

\section{Tool validation}

At this stage, face validity, content validity, and construct validity were performed. Reliability and validity were also evaluated. Face validity: Face validity was assessed by qualitative and quantitative methods and content validity by qualitative and quantitative methods respectively.

In the qualitative face validity, the items of the questionnaire were evaluated in terms of difficulty level, appropriateness, and ambiguity of items by five referring to obstetric triage. In quantitative formal validity, the impact index was used. Fifteen participants were asked to rate the importance of each item on the five-point Likert scale. If the impact score is equal to or greater than 1.5, the item is recognized as suitable for subsequent analysis(21).

Content validity: To determine the content validity, qualitative and quantitative methods were used. In reviewing the qualitative content validity, the researcher asked four instrumentalists, emergency gynecologists, obstetricians, and midwives to comment on clarity, simplicity, grammar use, appropriate words, placement of items in appropriate self-assessment, and appropriate scoring in written form $(21,22)$. To calculate the content validity ratio (CVR) quantitatively, 15 experts (Emergency Medicine, Gynecology, Reproductive Health, Midwifery) were asked to rank each item based on the three-point scale, 
"necessary, useful but not necessary, and not necessary" to check the necessity of the item. The expressions whose numerical CVR values above 0.49 were retained based on the Lawshe table (for 15 evaluates) to determine the minimum CVR(23).

In investigating the content validity index, the relevance of the items to the purpose of the research was evaluated from specialists (emergency medicine, gynecology, reproductive health, midwifery). To determine this index, 15 experts were asked to examine the relevance and adequacy of the items based on the four-point Likert scale. In this study, two indices, Item Content Validity Index (I-CVI) and Scale Content Validity Index (S-CVI) were calculated. The I-CVI represents the ratio of agreement on the relevance of each item. It is obtained by dividing the number of experts who rated the relevance or appropriateness of item 3 or 4 by the total number of experts. The validity index score above 0.79 is appropriate, $0.79-0.7$ is questionable and needs to be revised and a score below 0.7 is unacceptable and should be deleted $(22,24)$. The S-CVI acceptance criterion among toolmakers is 0.9 as the highest criterion and 0.8 as the lower content acceptance threshold (22).

Construct validity Exploratory factor analysis was used to determine the construct validity. In this study, according to the number of 10 items, 200 questionnaires were completed by the individuals referring to obstetrics triage considering the loss probability (25). The convenience method was used for sampling. The questionnaires were completed by those referring to obstetrics triage of hospitals in North, South, East, and Western areas affiliated to Shahid Beheshti University of Medical Sciences. To determine the adequacy of the sample, the Kaiser-Meyer-Olkin (KMO) test was used. The latent factors were extracted using maximum likelihood analysis and Promax rotation assuming the independence of the factors. In this model, two factors with eigenvalues higher than one were extracted. The cutoff point of 0.4 was considered, the minimum factor loading required for each statement to retain it.

\section{Reliability}

The reliability of the tool was assessed by internal consistency and Cronbach's alpha coefficient. An alpha coefficient above 0.7 was considered acceptable (26). To check the consistency of the obstetrics triage satisfaction questionnaire, the satisfaction questionnaire was completed by a sample of individuals ( 15 recipients of obstetrics triage service) in two stages with two weeks' interval and then scores obtained in two stages were calculated using intra-cluster correlation coefficient (ICC) test. The intra-cluster correlation coefficient of 0.7 and above denotes the optimal consistency.

\section{Interpretability}

A ceiling effect is said to occur when a high proportion of subjects in a study have maximum scores on the observed variable. This discriminates among subjects among the top end of the scale impossible, and the floor effect arises when a high proportion of subjects select the responses on the lower limit. The index should be less than $20 \%$ to include all criteria and show changes over time. In this study, the ceiling effect and floor effect was calculated for the total score of the questionnaire and the score of all subscales as a percentage to evaluate the scale discrimination and response distribution(27).

\section{Ease and feasibility}

Ease of use, ease of retrieval, and utility of the tool are defined in performance measurement. In this study, the percentage of unanswered questions and the percentage of answered cases were determined for each item.

\section{Statistical analysis}

Data were analyzed using SPSS-24 software and $p<0.05$ was considered a significance level.

\section{Results}




\section{Primary questionnaire}

The findings of the qualitative study showed that satisfaction with obstetrics triage is an important consequence of receiving midwifery and emergency triage services. Satisfaction with obstetrics triage is a multidimensional concept and involves satisfaction with structure and process.

Based on the findings of qualitative study and review of literature and review of similar tools and different studies, finally, 10 items were extracted. The items were placed as follows: Process Satisfaction (5 items), Structure Satisfaction (5 Items). Each item was scored on a five-point Likert scale (low, medium, high, very high).

Face validity: An item was modified (grammatically) in the investigation of qualitative face validity according to the opinion of 15 referrers to obstetrics triage. In determining quantitative face validity, the maximum impact of the item was obtained as five and the minimum impact score was 3.5 , and no item was eliminated at this stage.

Content validity: There were no revisions in the investigation of the qualitative content validity. At the quantitative content validity stage, the numerical CVR of all items was greater than 0.49 . The modified content validity index $\left(\mathrm{K}^{*}\right) \mathrm{I}-\mathrm{CVI}$ for all items ranged from 0.86 to 1 , and the S-CVI score was calculated as 0.97 .

Structural validity: Based on the KMO test on adequacy, the sample size was obtained as 0.89 that was at the acceptable level and Bartlett test was statistically significant $(p<0.0001)$. After fitting the exploratory factor analysis model with the PROMAX method, the 2-factor model was extracted from the logic of item arrangement and factor naming. The eigenvalues of the two extracted factors were 5.30 and 1.03, respectively. The two extracted factors account for about $63.40 \%$ of the total variance of the variables of the obstetrics triage satisfaction questionnaire. Thus, after performing factor analysis once, the items were assigned to the factor that had the highest factor loadings. Also, an item with a factor loading less than 0.4 was eliminated (Table 1). Figure one shows the scree plot diagrams explaining the components of the obstetrics triage satisfaction questionnaire.

Table 1

Eigenvalues and Explained Variance of Obstetrics Triage Satisfaction Questionnaire

\begin{tabular}{|c|c|c|c|c|c|c|c|c|c|}
\hline \multirow[t]{2}{*}{ Factor } & \multicolumn{3}{|c|}{ Initial Eigenvalues } & \multicolumn{3}{|c|}{$\begin{array}{l}\text { Sum of squares of factor loadings } \\
\text { before the epoch }\end{array}$} & \multicolumn{3}{|c|}{$\begin{array}{l}\text { Sum of squares of factor loadings } \\
\text { after the epoch }\end{array}$} \\
\hline & Total & $\begin{array}{l}\text { Variance } \\
\text { percentage }\end{array}$ & $\begin{array}{l}\text { Cumulative } \\
\text { percentage }\end{array}$ & Total & $\begin{array}{l}\text { Variance } \\
\text { percentage }\end{array}$ & Cumulative & Total & $\begin{array}{l}\text { Variance } \\
\text { percentage }\end{array}$ & $\begin{array}{l}\text { Cumulative } \\
\text { percentage }\end{array}$ \\
\hline 1 & $304 / 5$ & $04 / 53$ & $04 / 53$ & $30 / 5$ & $04 / 53$ & $04 / 53$ & $28 / 32$ & $88 / 32$ & $288 / 3$ \\
\hline 2 & $03 / 1$ & $35 / 10$ & $40 / 63$ & $03 / 1$ & $35 / 10$ & $40 / 63$ & $40 / 63$ & $51 / 30$ & $05 / 3$ \\
\hline 3 & $805 / 0$ & $05 / 8$ & $45 / 71$ & & & & & & \\
\hline 4 & $666 / 0$ & $66 / 6$ & $11 / 78$ & & & & & & \\
\hline 5 & $605 / 0$ & $05 / 6$ & $16 / 84$ & & & & & & \\
\hline 6 & $391 / 0$ & $90 / 3$ & $07 / 88$ & & & & & & \\
\hline 7 & $357 / 0$ & $57 / 3$ & $64 / 91$ & & & & & & \\
\hline 8 & $340 / 0$ & $40 / 3$ & $05 / 95$ & & & & & & \\
\hline 9 & $275 / 0$ & $75 / 2$ & $80 / 97$ & & & & & & \\
\hline 10 & $220 / 0$ & $19 / 2$ & $0 / 100$ & & & & & & \\
\hline
\end{tabular}


Table two illustrates the two factors extracted from factor analysis using the PROMAX rotation of factor loadings of their items.

Table 2

Factors extracted from factor analysis using PROMAX rotation and factor loadings of items

\begin{tabular}{|c|c|c|c|}
\hline \multirow[t]{2}{*}{ Naming of each factor } & \multicolumn{2}{|c|}{ Factor loadings } & \multirow[t]{2}{*}{ Items } \\
\hline & 2 & 1 & \\
\hline \multirow[t]{4}{*}{ Process Satisfaction } & & $837 / 0$ & Talking to the triage personnel about the client's anxiety and fear \\
\hline & & $836 / 0$ & Consultation with the client in making decisions about her care \\
\hline & & $784 / 0$ & Simplicity and clarity of triage personnel's explanations \\
\hline & & $645 / 0$ & Getting a description of triage personnel \\
\hline \multirow[t]{5}{*}{ Structure Satisfaction } & $791 / 0$ & & Physical space \\
\hline & $701 / 0$ & & Triage costs \\
\hline & $690 / 0$ & & Waiting time \\
\hline & $654 / 0$ & & Available facilities \\
\hline & $637 / 0$ & & Overall satisfaction with obstetrics triage \\
\hline Eliminated & $269 / 0$ & $276 / 0$ & Treatment of triage personnel \\
\hline
\end{tabular}

\section{Reliability}

The intra-cluster correlation coefficients for the whole tool and the two subscales of process and structure were $0.884,0.823$, and 0.846 , respectively. In this study, Cronbach's alpha for the whole tool was 0.793 , and Cronbach's alpha coefficient in case of omitting items was obtained (Table 3 ). 
Table 3.

Cronbach's alpha coefficient of each of the terms "obstetrics triage satisfaction" questionnaire

\begin{tabular}{|c|c|c|}
\hline No. & Item & $\begin{array}{l}\text { Cronbach's alpha coefficient in case of omitting } \\
\text { items }\end{array}$ \\
\hline 1. & Received explanation from triage personnel & $748 / 0$ \\
\hline 2. & Available facilities & $756 / 0$ \\
\hline 3. & Physical space & $757 / 0$ \\
\hline 4. & Triage costs & $760 / 0$ \\
\hline 5. & Waiting time & $748 / 0$ \\
\hline 6. & Total satisfaction with obstetrics triage & $754 / 0$ \\
\hline 7. & $\begin{array}{l}\text { Talking to the triage personnel about the client's anxiety } \\
\text { and fear }\end{array}$ & $737 / 0$ \\
\hline 8. & $\begin{array}{l}\text { Consultation with the client in making decisions about her } \\
\text { care }\end{array}$ & $741 / 0$ \\
\hline 9. & Simplicity and clarity of description of the triage personnel & $760 / 0$ \\
\hline
\end{tabular}

Finally, the first factor with four items and the second factor with five items were determined.Process Satisfaction Subsequently, each of the factors was named based on their items of process and structure satisfaction, which was consistent with the findings of the qualitative section (Table 2).

The ceiling effect of the tool was $5 \%$ and the floor effect was $0.5 \%$. In Table 4 , the ceiling effect and floor effect for the whole tool as well as the individual tool areas are listed.

Table 4

Ceiling effect and floor effect for the whole tool and the tool areas

\begin{tabular}{|lllll|}
\hline Factor & $\begin{array}{l}\text { Frequency of minimum } \\
\text { score }\end{array}$ & $\begin{array}{l}\text { Floor effect } \\
\text { (\%) }\end{array}$ & $\begin{array}{l}\text { Frequency of maximum } \\
\text { score }\end{array}$ & $\begin{array}{l}\text { Ceiling effect } \\
\text { (\%) }\end{array}$ \\
\hline Process satisfaction & 7 & $5 / 3$ & 23 & $5 / 11$ \\
\hline $\begin{array}{l}\text { Structure } \\
\text { satisfaction }\end{array}$ & 1 & $5 / 0$ & 21 & $5 / 10$ \\
\hline Total & 1 & & 10 & 5 \\
\hline
\end{tabular}

To facilitate responsiveness in this study, precise item analysis and factor analysis were performed to prevent tool prolongation. Also, none of the items was unanswered.

\section{Scoring the tool}

The tool has five-point Likert scale options (1-5) with answers from 5 options: never, low, medium, high, and very high. The following scores are awarded to options: never (1), low (2), medium (3), high (4), and very high (5). The tool is scored using 
the formula $\times 100 \frac{\text { Score-min }}{\text { Mzx-Min }}$ on a hundred basis. The higher scores in the present tool will denote higher satisfaction.

\section{Discussion}

This study, for the first time in Iran and the world, presents a reliable and valid tool for assessment of obstetrics triage satisfaction. The questionnaire consists of two subscales of structure and process. Obstetrics triage satisfaction is defined as understanding the concept of clients' satisfaction with the structure, space, and activities of the triage unit, and how they are performed according to guidelines and standards as well as the treatment of triage personal. Since service satisfaction is an important indicator in evaluating the quality of services provided in the health system $(9,10,28)$, and obstetrics triage is one of the major concerns of hospitals and the health system, developing and extending obstetrics triage satisfaction tool as a valid and reliable tool is essential to assess clients 'satisfaction with midwifery triage, identify challenges and problems, specify causes of clients' dissatisfaction and their needs, and plan appropriately to address challenges and problems.

Although it is critical to measure it, the main criticism is that many of the tools used to measure patient satisfaction are not valid and reliable (standard), while the instrument must have sufficient power to determine results (29).

In the present study, the satisfaction with the process was less than the satisfaction with the structure. This finding indicates that the process of service delivery is more important than the structure and physical space of service delivery for the clients. According to the Donabedian model, the path to assess the quality of care starts with the structure (having the right objects and supplies), then moving on to the process (doing the right things) and eventually ending in the outcome (doing the right thing and satisfaction). Assuming the provision of the minimum appropriate structure, the process is an essential element in quality assurance. Even if the causal relationship between care delivery processes and their end-results is not consistent, continuous attention to the process can achieve the desired results(8, 30-31).

In the process satisfaction dimension, the highest factor loading is related to talking with triage personal about the client's anxiety and fear. The results of studies have shown that two important elements in the patient-centered relationship are drawing out and responding to the patient's real fears and concerns. Removing all patient concerns in the first referral is as easy as this question: "Is there anything else you're worried about?" Although the pressures of lack of time are real, service providers, even if they have enough time, often ignore paying attention to the fears and worries of clients (32).

In the structure satisfaction dimension, the highest factor loading is on the physical space. The results of studies have shown that physical environment and space are important factors in triage satisfaction and satisfaction can be enhanced by creating a proper and appropriate triage system and orderly and comfortable space (33).

Since no studies have been conducted to design and psychometrically evaluate tools for obstetrics triage satisfaction, the findings of this study are compared with those of similar tools. McKinley RK Et al. designed a tool for assessment of patients' satisfaction with receiving out of hours primary care. The tool consists of 32 items (20 of which are related to teleconsultation), and 6 subscales (Satisfaction with communication and management, physician attitudes, waiting time, continuity of care, access to out-of-hours care, telephone counseling). Its nonresponse was $96.5 \%$ with $61 \%$ variance. The internal consistency of several subscales is less than 0.7 (34).

Garratt et al. designed a tool to measure patient experiences for out-of-hours primary care. The tool consists of 24 items (10 of which are related to teleconsultation), and 4 subscales (medical services, call contact and organization, nursing services, unanswered questions). Its nonresponse rate was $96.5 \%$ with $79 \%$ variance. Internal consistency was higher than 0.80 (35). Moll van Charante et al. designed a tool to assess patients' satisfaction with out-of-hours primary health care. The tool consists of 66 items (14 of which are related to teleconsultation), and 3 subscales. The construct validity was assessed by PCA and the percentage of variance for each factor was 77.72 and $89 \%$, respectively. Its response rate for teleconsultation was $36-57 \%$ and internal consistency was above 0.70 for all factors. Content and face validity information was not mentioned (36). 
Compared to existing tools, this tool not only examines satisfaction with the way tasks are handled and the client is treated during the triage process (satisfaction with the process), but also examines satisfaction with the physical structure, space, and equipment of the obstetrics triage, while other tools focus only on the service delivery process. On the other hand, the tool is very short compared to the size of other tools.

The present questionnaire can be considered as a new questionnaire in Iran and worldwide. One of the strengths of this questionnaire is that the main constructs of it have been extracted and identified after defining the concept of satisfaction with obstetrics triage through a qualitative content analysis approach. One of the limitations of the present study is the lack of convergent validity due to the lack of similar tools in this field.

\section{Conclusion}

The obstetrics triage satisfaction questionnaire is a valid and reliable questionnaire for the assessment of the satisfaction of clients with obstetrics triage. The questionnaire consists of nine items with two dimensions (process and structure satisfaction) of five-point Likert scoring is a simple and easy-to-use tool. This questionnaire may help health providers and policymakers identify problems and challenges in triage that lead to dissatisfaction and inappropriate outcomes and take appropriate action as appropriate.

\section{Abbreviations}

SATOT: Satisfaction Assessment Tool for Obstetrics Triage

ICC: Intra-Cluster Correlation Coefficient

CVR: Content Validity Ratio

I-CVI: Item Content Validity Index

S-CVI: Scale Content Validity Index

KMO: Kaiser-Meyer-Olkin

PCA: Principal Component Analysis

\section{Declarations}

\section{Ethics approval and consent to participate}

Ethics approval was obtained from the Ethics Committee, Faculty of Pharmacy and Nursing Midwifery, Shahid Beheshti University. Informed written consent was obtained from all participants.

\section{Consent for publication}

Not applicable.

\section{Availability of data and materials}

The datasets used and/or analysed during the current study are available from the corresponding author on reasonable request.

\section{Competing interests}

The authors have no conflicts of interest relevant to this article. 


\section{Funding}

This study was supported by a grant from the Research Council of Shahid Beheshti University of Medical Sciences.

\section{Authors' contributions}

FR: Project development, Data Collection, Manuscript writing,

MS: project administration, writing-review, and editing, supervision

All authors have read and approved the final manuscript.

\section{Acknowledgments}

The authors appreciate the cooperation and assistance of the officials of Taleghani, Mahdyieh, Emam Hossein, Loqman, and Shohadaye Tajrish Educational Hospital. We are greatly thankful to participate.

\section{References}

1. Grossman VG. Quick reference to triage: Lippincott Williams \& Wilkins; 2003.

2. Matteson KA, Weitzen SH, Lafontaine D, Phipps MG. Accessing care: use of a specialized women's emergency care facility for nonemergent problems. Journal of Women's Health. 2008;17(2):269-77.

3. Angelini DJ, Stevens E, MacDonald A, Wiener S, Wieczorek B. Obstetric triage: models and trends in resident education by midwives. Journal of Midwifery \& Women's Health. 2009;54(4):294-300.

4. Zocco J, Williams MJ, Longobucco DB, Bernstein B. A systems analysis of obstetric triage. The Journal of perinatal \& neonatal nursing. 2007;21(4):315-22.

5. Rashidi Fakari F, Simbar M, Rousta R, Rashidi Fakari F, Mosaheb A, Saei Ghare Naz Mea. Mean waiting time in obstetric triage. The Iranian Journal of Obstetrics, Gynecology and Infertility. 2019;22(10):35-41.

6. Wuerz RC, Travers D, Gilboy N, Eitel DR, Rosenau A, Yazhari R. Implementation and refinement of the emergency severity index. Academic Emergency Medicine. 2001;8(2):170-6.

7. Rashidi-Fakari F, Simbar M, Safari S, Zadeh-Modares S, Alavi-Majd H. The Quality of the Maternity Triage Process: a Qualitative Study. Advanced Journal Of Emergency Medicine. 2020;4.

8. Organization WH. Consultation on improving measurement of the quality of maternal, newborn and child care in health facilities. 2014.

9. Wolf J. A Report on the Beryl Institute Benchmarking Study: The State of Patient Experience in American Hospitals. Bedford, TX: The Beryl Institute; 2011.

10. Fenny A, Enemark U, Asante F, Hansen K. Patient Satisfaction with Primary Health Care - A Comparison between the Insured and Non-Insured under the National Health Insurance Policy in Ghana. Global Journal of Health Science.

2014;6(4):9-21.

11. Wen J, Schulman K. Can team-based care improve patient satisfaction? A systematic review of randomized controlled trials. PloS one. 2014;9(7).

12. Turner PD, Pol LG. Beyond patient satisfaction. Marketing Health Services. 1995;15(3):45.

13. Dibaei A, Saadati N, Zadeh MZ. Patients Satisfaction with the Medical Services of the Emergency Department during holidays: A Survey in three main Hospitals Affiliated to Ahvaz Jundishapur University of Medical Sciences. Biomedical \& Pharmacology Journal. 2015;8(2):1187-94.

14. Bailey ED, Sweeney T. C Onsiderations In E Stablishing E Mergency M Edical S Ervices R Esponse T Ime G Oals. Prehospital Emergency Care. 2003;7(3):397-9. 
15. Garratt AM, Danielsen K, Hunskaar S. Patient satisfaction questionnaires for primary care out-of-hours services: a systematic review. Br J Gen Pract. 2007;57(542):741-7.

16. Fakari FR, Simbar M. Obstetric Triage Scales; a Narrative Review. Archives of academic emergency medicine. 2019;7(1).

17. Changaee f, Simbar m, Irajpour a, Akbari s. Strategies to improve quality of childbirth care. scientific magazine yafte. 2015;16(3):22-33.

18. Evans M, Watts N, Gratton R. Women's satisfaction with obstetric triage services. Journal of Obstetric, Gynecologic \& Neonatal Nursing. 2015;44(6):693-700.

19. Graneheim UH, Lundman B. Qualitative content analysis in nursing research: concepts, procedures and measures to achieve trustworthiness. Nurse Educ Today. 2004;24(2):105-12.

20. Graneheim UH, Lundman B. Qualitative content analysis in nursing research: concepts, procedures and measures to achieve trustworthiness. Nurse education today. 2004;24(2):105-12.

21. Polit D, Beck C. Essentials of nursing research: Appraising evidence for nursing research. Baltimore: Lippincott Williams and Wilkins; 2013.

22. Ebadi A, Zarshenas L, Rakhshan M, Zareiyan A, Sharif nia H, Mojahedi M. Principles of scales development in health science. Tehran: Jmeenegar; 1396.

23. Wilson FR, Pan W, Schumsky DA. Recalculation of the critical values for Lawshe's content validity ratio. Measurement and evaluation in counseling and development. 2012;45(3):197-210.

24. Waltz CF, Strickland OL, Lenz ER. measurement in nursing and health research. 4th edition. New York: Springer Publishing Company; 2010.

25. MacCallum RC, Widaman KF, Zhang S, Hong S. Sample size in factor analysis. Psychological methods. 1999;4(1):84.

26. Krause SA, Graves BW. Midwifery triage of first trimester bleeding. Journal of nurse-midwifery. 1999;44(6):537-48.

27. Dilorio CK. Measurement in health behavior: methods for research and evaluation: John Wiley \& Sons; 2006.

28. Rashidi Fakari F, Simbar M, Safari S, Rashidi Fakari F, Moghadas Inanloo E, Molaie L. Explaining the quality index of obstetric triage. Hayat, Journal of School of Nursing and Midwifery, Tehran University of Medical Sciences. 2020;25(4):356-65.

29. Kleefstra S, Kool R, Veldkamp C, Winters van der meer A, Mens M, Blijham G, et al. A core questionnaire for the assessment of patient satisfaction in academic hospital in the Netherlands: development and first result in a nationwide study. Qual Saf Health Care. 2010;19(5):e24.

30. Donabedian A. An introduction to quality assurance in health care: Oxford University Press; 2002.

31. Donabedian A. Evaluating the quality of medical care. The Milbank Quarterly. 2005;83(4):691-729.

32. Epstein RM, Mauksch L, Carroll J, Jaen CR. Have you really addressed your patient's concerns? Family practice management. 2008;15(3):35.

33. Soleimanpour H, Gholipouri C, Salarilak S, Raoufi P, Vahidi RG, Rouhi AJ, et al. Emergency department patient satisfaction survey in Imam Reza hospital, Tabriz, Iran. International journal of emergency medicine. 2011;4(1):2.

34. McKinley RK, Manku-Scott T, Hastings AM, French DP, Baker R. Reliability and validity of a new measure of patient satisfaction with out of hours primary medical care in the United Kingdom: development of a patient questionnaire. Bmj. 1997;314(7075):193.

35. Garratt AM, Danielsen K, Forland O, Hunskaar S. The Patient Experiences Questionnaire for Out-of-Hours Care (PEQ-OHC): data quality, reliability, and validity. Scandinavian journal of primary health care. 2010;28(2):95-101.

36. Moll van Charante E, Giesen P, Mokkink H, Oort F, Grol R, Klazinga N, et al. Patient satisfaction with large-scale out-ofhours primary health care in The Netherlands: development of a postal questionnaire. Family practice. 2006;23(4):43743.

\section{Figures}

Page $11 / 12$ 


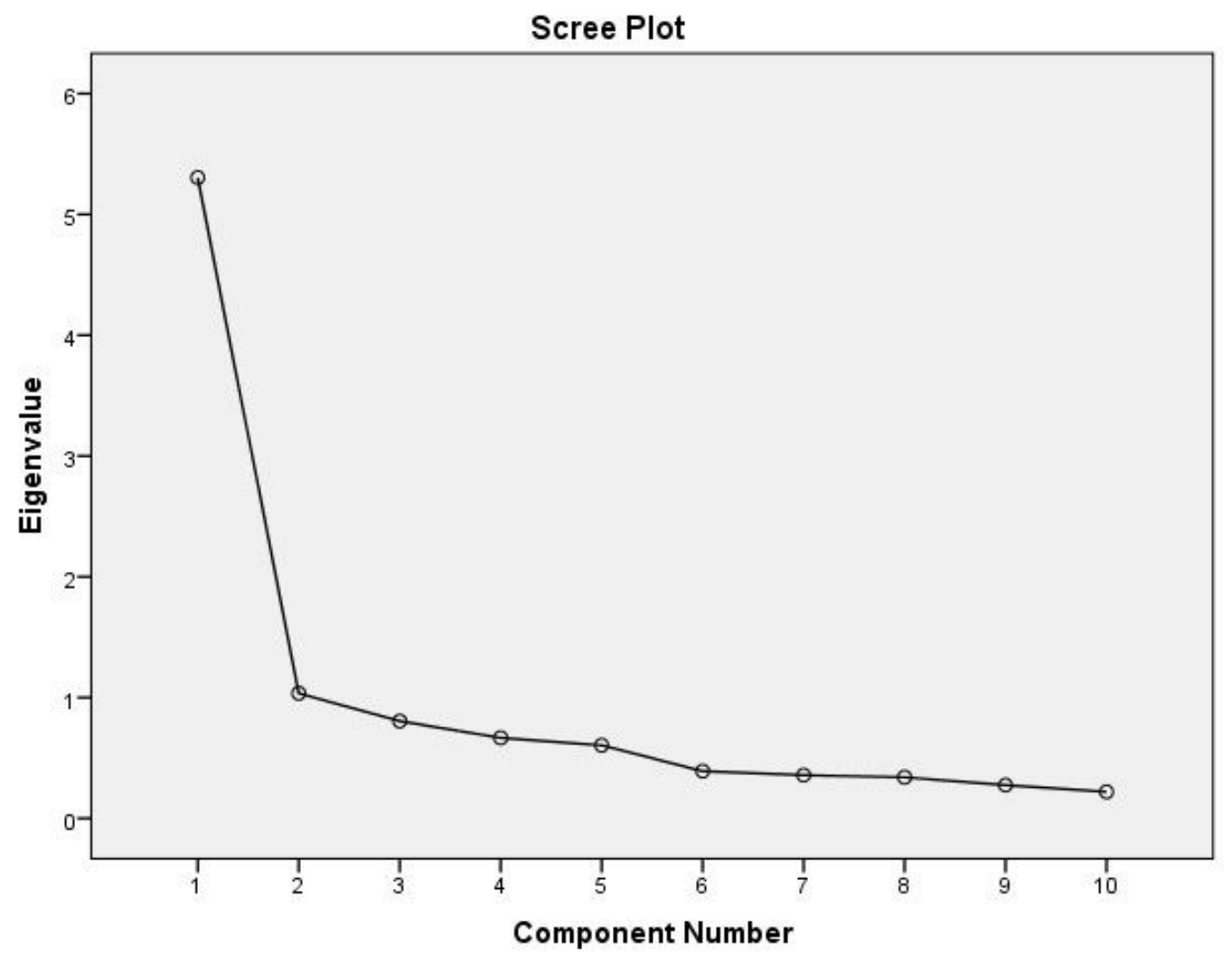

\section{Figure 1}

Scree plot diagram explaining components of obstetrics triage satisfaction questionnaire

\section{Supplementary Files}

This is a list of supplementary files associated with this preprint. Click to download.

- englishlanguageversion.docx 